\title{
Supra Segmental Phonology in Skaka Dialect and Its Relation to the Modern Standard Arabic
}

\author{
Atalah Al-Rubaat*, Anas Ahmed Qarqaz \\ Department of English, College of Arts, Jouf University, Sakaka, KSA \\ Email: *amsardi@ju.edu.sa
}

How to cite this paper: Al-Rubaat, A., \& Qarqaz, A. A. (2019). Supra Segmental Phonology in Skaka Dialect and Its Relation to the Modern Standard Arabic. Open Journal of Modern Linguistics, 9, 330-342. https://doi.org/10.4236/ojml.2019.95027

Received: August 10, 2019

Accepted: September 24, 2019

Published: September 27, 2019

Copyright (c) 2019 by author(s) and Scientific Research Publishing Inc. This work is licensed under the Creative Commons Attribution International License (CC BY 4.0).

http://creativecommons.org/licenses/by/4.0/

(c) (i) Open Access

\begin{abstract}
This study aimed at identifying and documenting some linguistic phenomena in the temporary dialect of Skakans at Al-Jouf region in the northern part of Saudi Arabia. Two major linguistic phenomena: the Istintta and the Kaskasa have been investigated. The study has also interpreted and originated these phenomena taking into consideration their possible relationship with the Classical Standard Arabic (SA) and Semitic languages. A random sample of Skakan people (tribal) was interviewed through a semi-structured interview format based on a deep review of related literature. Data gathered were analyzed using a mixed methodology employing the descriptive approach to analyze and interpret these linguistic phenomena and the historical approach to trace their origins and find out their relationship with the SA and Semitic languages. Content analysis and comparative approaches were also used. Findings indicated that the relationship between the investigated phenomena and the SA was strong in certain cases and weak in others. It was concluded that this instable relationship was beyond avoiding documenting the dialects of people living around the Arabian Peninsula borders by old Arab Linguists.
\end{abstract}

\section{Keywords}

Sakak Dialect, Modern Arabic, Standard Arabic, Supra Segmental, Linguistic Phenomena, Istintta, Kaskasa

\section{Introduction}

Two different views regarding the Arab tribes living in the Arabian Peninsula were adopted by the old linguists: the first believed that some tribes were superior to others, and thus their dialects were fully or partially a clear pattern of Standard Arabic. For example, there was a census among most Arab linguists, poets and novelists that Quraysh tribe represented the highest rank of Standard 
Arabic speakers (Ibn-Fares, 1997). Another evidence supporting this view is found in Hawazen Tamim tribes such as Sad bin Bakr tribe, Jusham Bin Bakr tribe, Nasser Bin Muawiaa tribe and Thaqief tribe according to Al-Suyuti (1998). The second degraded the tribes residing around the boundaries of the Arabian Peninsula describing their linguistic variations with extremely negative features such as bad, denied, or even ugly. In certain occasions, some linguists ignored some dialects leaving them unnamed or described. These latter attitudes continued by successive linguists and scholars for along age until they were consolidated and related dialects became less important than SA for any language study.

Ignoring documenting and considering the dialects of people who lived around the Arabian Peninsula borders were mostly due to linguistic misconceptions. For instance, it was believed that studying the dialects like Istintaa and Kaskasah which are the main issue of this research might have diminished, weakened or threatened the high position of SA. One example of the first phenome (Istintaa) is the word /anta/ meaning "to give" which is originally pronounced as /a?ta/ in SA. The former utterance (anta) may refer to inferiority of tribes using it. Therefore, the problem of this research stemmed from the fact that there was a big misunderstanding of the relationship between local dialects of the north border Arabian region and that of SA.

In other words, the phenomena under investigation were used to be misunderstood and mostly used as a reference for non-standard Arabic. For example, if one uses /batsir/ as a common word in kaskasah instead of the word "bakir" commonly used in SA where both are identical in meaning (tomorrow), he/she was viewed as a user of non-SA. Another example is the word Hatsi instead of the SA word "haki", where both mean the same as of the word "speech".

While some Arabic dialects were ignored, it has been proved, at least from a sociolinguistic point of view that the study of dialects could significantly help in understanding a number of academically unresolved linguistic issues. It was also evident that the study of dialects could resolve issues of unconsidered or degraded languages. The study of dialects has also proved that possible impacts could occur as a result of the interaction between languages, within one linguistic faction, or even between divergent factions i.e., the "Affect and Influence" as a universal inter-languages phenomenon may not be excluded from the study of the linguistic phenomenon under investigation. The dialect of Sakakans was one of those dialects that linguists distanced themselves from; however, their use survived until today.

The linguistic phenomena being studied are used by many people in the north region of Saudi Arabia with specific concentration in Sakaka city which is located at Al Jouf valley. Surrounding towns were historically known since the Assyrian era. Sakaka was also known during the Aramaic period, which ruled Iraq and Syria, and expanded to Egypt and part of Saudi Arabia. The Aramaic period coincided with Nabataea's for some time where the two languages almost disappeared from Sakaka after the Islamic conquest of Aljouf Region, which strengthened the SA in the region. However, the overlap and interrelatedness of 
the three languages: SA, Aramaic and Nabataea remained evident in research papers.

\section{Rationale}

This research is linguistically significant for various factors. First, its findings will shed light on the origins and movement of some old and current spoken dialects of people who have lived in the north region of KSA for a long history. In other words, these findings would enable linguists to identify some of the investigated linguistic phenomena and relate them to their origins appropriately. Second, the findings would also help sociolinguists attain deeper understanding of the local norms of Arabs live in the north borders of KSA; and thus, establish concrete evidence on their dialects in the contemporary Arabic dictionaries. Further, this research would provide a scientific relevant data base of the linguistic phenomena under investigation and enable future research conduct further investigations in the related linguistic phenomena in the region and cross-KSA northern borders.

Generally, this research attempted to answer the following questions:

1) Are the linguistic phenomena: Istintta and Kaskasa normal dialects of SA?

2) Were the linguistic phenomena: Istintta and Kaskasa ignored from documentation by old linguists for reasonable argumentation?

3) Was the dialect of original Sakakans affected by neighboring non-Arabic languages?

Data were gathered by applying deep review of previous related literature as a basis for conducting semi-structured interviews with people living in the area under investigation. This instrument (interview format) has been defined as "a conversation between interviewer and interviewee with a purpose (Dexter, 1970; Moser \& Kalton, 1971) or as "a guided conversation" (Lofland \& Lofland, 1984: p. 2). The sample of interviewees was selected randomly from Arab tribes in the northern region of KSA representing people from mixed backgrounds: old, middle-aged and young people, males and females, educated of various degrees and illiterate, rural and urban people.

The interview is different from a conversation in that it is directed for pre-determined goals in mind (Keats, 2000). For example, Cohen (1976) remarks that an interview should be carefully prepared with much attention and deep expertise since it digfs deep in the interviewee's background and context, which may be noticed easily. For example, interviewing people of different social and language backgrounds in a wide region like Sakak and Aljouf at KSA, would definitely reflect this method used in collecting data of the research.

All observations and interviews were recorded and transcribed for documentation and further analysis. The researchers employed a mixed methodology to analyze the gathered data focusing mostly on the descriptive approach to identify the investigated linguistic phenomena, and the comparative approach to originate those phenomena. 
Since this research was conducted on the Skakans' dialects in the present era, the findings of this research may not be generalized to other regions, peoples or different period of time. The research has investigated two main linguistic phenomenon known as Istintta and kaskasah; so the results may not be generalized to other linguistic phenomena. The following sections display and discuss the literature of the linguistic phenomena being considered before discussing and interpreting them in light of the findings. Finally, the conclusion and implications of the research are included.

\section{Literature Review}

Words, as one of the most salient linguistic constituent of any language, and as linguistic evolutionary phenomena, have moved geographically from one location to another with their native speakers over ages. As a result of this movement and due to the early social mix up of tribes who used those words, new linguistic phenomena and new semantic indications have emerged. These linguistic phenomena are still in use and live in the 21st century. However, it has been observed that many young people do not distinguish between some of the various usages of these words due to the complicated mix up between various Arab tribes in the region.

Such different uses of words by people of various tribes are historically evident. Many previous researches have also supported this phenomenon indicating the fact that various languages and dialects normally borrow utterances, words or even pronunciation of some words from each other; whether these languages are old or modern. Therefore, the linguistic borrowing phenomenon, or as being called by scholars, Influenced or Influential, is normal amongst languages. Logically, no one language can survive communicatively in isolation from other languages due to the normal mix up of people from various origins and languages for various objective purposes such as trade, politics and others. Therefore, words can move from its original emergent region to another with no need for its speakers to travel with.

In this context, classical/standard Arabic, as one of the Universal languages, has received unprecedented care by old or contemporary scholars and linguists. This apparent care started along the First Abbasid Era (719-816) in the second Hijri century. The Writing, which was almost ignored before then became a significant manifestation of the nation development. At that era, linguists started writing the classical Arabic language relying on Arab tribes which considered it a high fluency criterion. Those linguists limited their writing of the Classical Arabic language within a limited period, known as the Linguistic Argumentation Era. As a result of this limitation dialects of many tribes were excluded, and thus kept departed from the circle of Arabic fluency. Their so-called non-fluent variants were then described as corrupted or degenerated and started to be known as "Denied Languages" (Al-Suyuti, 1998).

These "denied languages" were also described in Al-Muzhir As “...the ugliest 
and lowest languages specially their linguistic phenomena: Kashkasha, Kaskasa, Fahfaha, Watm, Wakm, and others..." (Al-Suyuti, 1998: p. 176). However, in general, none of the dialects of the cities dwellers or inhabitants of wilderness in the surrounding of the Arab peninsula were considered in that era of fluency. Perhaps the argumentation beyond this consideration was because those people were closer in location to the nearby nations and ought to have been affected by their languages. For instance, Lakhm and Jutham tribes were near Egyptians and Qubts, Qudha'a, Ghassan, and Iyaad Tribes were adjacent to the people of Syria who were mostly Christians reciting non-Arabic in their prayers, or Bakr tribe who were close to the Nabateans and Persians (Ramadan, 1999a, 1999b: p. 104).

The Writing Era was confined to recording the high standard language and ignoring the other "inferior" dialects. Therefore, languages mixed with non-Arab nations were not considered. The Arab Nabataeans were found to speak the Aramaic tongue, and later the Syrians Christians continued their connections with Arabs until today. This indicates the Arab linguists care not to mix their language with others. However, ignoring languages or dialects that mixed with other languages contributed to the vagueness of some linguistics phenomena, and thus remained unresolved. Arguments about interpreting such phenomena were complex and unclear due to the interrelatedness of those phenomena or some and their interrelation with the standard Arabic which have never been pointed to. Perhaps the only reasonable interpretation of such dilemma is that any language can never survive in isolation of other languages, besides that Arabic with its long history had not been recorded or written earlier.

\section{Phenomenon: Pharyngeal Sounds /S/}

\section{Istentaa Phenomenon}

The substitution /alteration/ replacement (Istenttaa) is one of the linguistic phenomena that were studied by the old linguists in reference to the substitution of one letter (sound) by another. The linguists categorized this phenomenon into five sections: the first refers to the replacement of sounds with closer in their place of articulation than others such as: /?/and /h/. The second refers to the substitution between sounds with between adjacent (but not closed) articulators such as $/ \mathrm{h} /$ and $/ \mathrm{h} / \tau$ pharyngeal voiceless fricative. The third refers the substitution between sounds with neighboring articulators such as /d/ and / $\dot{z} / \dot{j}$. The fourth refers to the substitution between the sounds of similar phonemic characteristics and non-adjacent articulators such as $/ \mathrm{m} /$ and $/ \mathrm{n} /$. The fifth is the substitution between the sounds with no phonemic characteristics and non-closed articulators such as $/ ؟ /$ and $/ \mathrm{n} /$ which is the focus of this research know by linguists as the substitution or "istinttaa".

Some dictionaries stated the word /anta/ refers to the same meaning of the word /aSta/ (gave), both with same meaning of Arabic gerunds /intaa/ and /iStaa/. Linguists described this phenomenon as alteration of the consonant sound /S by the sound /n/ if it comes adjacent to the sound $/ \mathrm{t} / \mathrm{such}$ as that of 
/anta/ in the word /a?ta/. The surface description of this phoneme indicates that if the consonant sound / $/ \mathbf{l}$ followed the sound / $\mathrm{t} /$ at any word, it will be altered into the sound /n/ for some trines. Similarly, in the word /atasha/ meaning (gets thirsty), and other words including /atafa/, /meSteer/ and /j9tis/. Therefore, the phenomena here are extended and unremitting. A confusing similar example to the past form /anta/ or /aSta/ for some scholars and was mentioned in dictionaries is the word /natshan/ which altered the word //atshan/ meaning (thirsty). Ibn-Fares (1991, p. 128) commented on such a claim that "it is invalid and may not be misleading scholars"

Tracing this phenomenon at its origins, it has been revealed for scholars that the phonological conditioning rule was not extended or generalizable. In other words, the "istintaa" is not an absolute replacement, alteration or substitution for the silent $/ \mathbf{S} /$ if it was followed by the sound $/ \mathrm{t} /$, rather it is confined to the verb /aSta/ only and its derivational forms, whether in altering the sound / $/ \mathbf{S}$ into the sound $/ \mathrm{n} /$ or vice versa as will be indicated later.

Various linguistic texts mentioned the "istintaa" phenomenon including some Quranic readings and prophetic Hadiths, though these hadiths were not authentic according to some Hadith scholars. Arabic dictionaries also have referred to some poetic evidence that confirms the existence of the phenomenon in certain Arab tribes.

The phenomenon was attributed to a number of Arab tribes. It was claimed that it is related to the ancient Arabs or Quraish (Abu-Hayyan, 2001: p. 520), the people of Yemen, Bani Saad (Al-Zamakhshari, 538 H.: p. 17), bin Bakr, Huthail, Al-Azd, Qays, and Al-Ansaar (Al-Suyuti, 1998: p. 176). These tribes are all Yemenis except Huthail. The phenomenon is still widely used in Iraq (Ramadan, 1999a, 1999b: p. 121), northern part of Jordan, some areas of Palestine, the Syrian desert, the city of Sakaka, specifically in the Shalhoub neighborhood, which is inhabited by the of Saraheen Tribe (Al-Sarhan).

The phenomenon at these locations is limited only to the word /anta/ or /aSta/ which shed light on the multiplicity in the spread of this phenomenon and other linguistic phenomena. i.e., the Arab tribes that uses this phenomenon and alike are located on the roads of caravans, from north to south, or as called in the Holy Quran "the Caravans of Winter and Summer" (Ramadan, 1999a, 1999b: p. 121). The researchers believe that the spread of the phenomenon is dependent upon the transfer of some Arab tribes and their movement of residence from one place to another in their pursuit for water and food resources. This latter interpretation could be more reasonable for the phenomenon spread than the former one. One further reason for the spread of the phenomenon is the mixing of various tribes and peoples in the religious seasons, trade occasions, or the wide spread wars in-between a large number of the Arab world, where each linguist narrate what have been received of those tongues.

"Istintaa" was mentioned in a number of linguistic manifestations such as the Quranic readings (e.g., Al-Hassan bin Massrif ((Al-Qurtubi, 1964: p. 216) and 
Ibn Muhaisin Al-Zafarani /antainanka/) (Abu Hayyan, 745 H.: p. 520). Other examples were mentioned in the Prophetic Hadith in a letter sent from the Phrohet (PBUH) and written down by Ali bin Abi Talib "From Mohammed, the Messenger of Allah ... and /anto/ althabaja", This format of the letter might have been consistent with the tongue of Yamanis regarding this phenomenon of istinta. Similarly, the Sharif (noble) /inta/ letter from the Prophet (PBUH) to his great companion Tamim Addari Al-Lakhmi Al-Filistini. The letter was written in the format of Intaa that was consistent with the tongue of Tamim Tribe and followers: "In The Name of Allah, the Most Gracious, The Most Merciful, this is what Mohammad, the Messenger Of Allah (PBUH) anta (gave) to Tamim and his companions. antaitukum (I gave you) Ain hebron... and all are absolutely be absolute given mantiyah (Al-Khattabi, 1982: p. 15/281; Al-Zamakhshari, 538 H: p. 17).

The letter of Al-Mugheerah bin Shubaah to Muawiyah bin Abi Sufyan (May Allah Satisfy them both) is another evident of the phenomenon, where the latter wrote to Al-Mugeerah: write to me some of you heard from the Prophet $(P B U H)$, Al-Mugheerah replied saying: I heard him saying' if victory it is from prayers... o' Allah, nothing can prevent what you give, and no giver can give what you prevent, and nothing can get used from your sources o the Lord of all sources. It was narrated as "No giver (Munti /mu?ti/)". The prophet also said "the (munti's) giver's hand is better than the lower hand" (Ibn al-Atheer, 606 $\mathrm{AH})$.

Some of the poetic evident that the old books included intensively what was narrated about Al-?sha (Abu-Hayyan, $745 \mathrm{H}$ : p 520),

\begin{tabular}{|c|c|c|}
\hline Arabic Version & تُصَان الجِلالَ وتُتْطَي الثَّعِيرا & جِيادُك خَيرُ جِيادِ الملُوك \\
\hline English Transcription & Jiaduka khairu jiaidi almuluki & tusanu aljilala wa tunda alshaSira \\
\hline Translation Into English & Your horses are the best ever & $\begin{array}{c}\text { ir dung is kept and they are barely fed } \\
\text { tunta (fed) }\end{array}$ \\
\hline
\end{tabular}

Another example is for Thalab (Ibn-Manthoor, 711: p. 333) composing:

\begin{tabular}{|c|c|c|}
\hline Arabic Version & يُرَى، فِي فُرُوع المُقْتَتَينِ، نُضُوبُ & مِنَ المُنْطِياتِ المَوْكِبَ المَعْجَ بَعْدَ ما \\
\hline English Transcription & $\begin{array}{l}\text { Yura fi furo@i almuqlataini } \\
\text { nudhubun }\end{array}$ & $\begin{array}{l}\text { min almuntiyati almawkibi almeSja } \\
\text { baSdama }\end{array}$ \\
\hline Translation Into English & $\begin{array}{c}\text { Some of the muntiati (given) } \\
\text { are miracles after }\end{array}$ & seeing depletion in the eyes \\
\hline
\end{tabular}

The most common expression these days occurs in Sakaka as the:

\begin{tabular}{cc}
\hline Arabic Version & \multicolumn{1}{c}{ ينطيك العافية } \\
\hline English Transcription & Yantafiah \\
Translation Into English & May allah give you the perfect health. \\
\hline
\end{tabular}




\section{Second Phenomenon: Platal Sounds /k/ \\ Kaskasah Phenomenon}

Kaskasah Phenomenon is called so due to the meeting of the /s/ sound and $/ \mathrm{k} /$ in a word. Kaskasah is a word generated (Ibn-Fares, 395 H.: p. 128), referring to an old-rooted linguistic phenomenon with many formats according to some linguists as follows:

- to match the sound / $/ \mathrm{k} /$ with that of /s/ to be pronounced as /alaikes/ as attributed to Rabeea' (Ibn-Fares, 395 H.: p 29) and Bakr tribes (Al-Mabrad, 285 H., p. 166).

- to switch the sound $/ \mathrm{k} /$ or replaced it in masculine nouns or pronouns by the /s/ sound referring to the difference between both of them as attributed to Rabia, and Mudhar (Al-Suyuti, 911 H.: p 176).

\section{Discussion}

\subsection{First Phenomena}

As mentioned earlier the alteration occurs in the linguistic phonemes especially in those of one place of articulation and close phonetic features. Istinttaa phenomenon is a good example of the divergence and separation in articulators where, for example, the $/ \mathrm{S} /$ and /n/ are far from being unified in spite that their features are close. The / $/$ / is a voiced laryngeal soft sound (Ramadan, 1999a, 1999b: p. 121) according to the description of the laboratory experiments in the modern era (Ramadan, 1997: pp. 33-37). As for the /n/, it is a voiced nasal sound pronounced by pressing the tip of the tongue against the sides of the alveolar ridge, lowering the palate and opening the nasal duct causing a vibration in the vocals. Being a nasal sound means that the air out of the lungs passes through the cavity of the nose causing a kind of swish (Ramadan, 1997: p. 82). It is also a central sound since it is not hard or soft (Ramadan, 1997: p. 49). Therefore, the two sounds are similar in regard to the voice characteristics and different in that the first is soft and the latter is central.

\begin{tabular}{cccc}
\hline Sound & Place of articulation & Voice $(+/-)$ & Manner of articulation \\
\hline$/ \mathrm{S} /$ & Pharyngeal & Voiced & Fricative/approximant \\
$/ \mathrm{n} /$ & Alveolar & Voiced & Nasal \\
\hline
\end{tabular}

The study of modern linguistics opposes classifying this phenomenon as an alteration, nor does it agree with altering the /n/ sound (Ramadan, 1999a, 1999b: p. 121) due to the difference in the place of articulation and features between the two phonemes without which alteration would occurs in every word with these two neighboring sounds. For old linguists, the similarity in some features could be beyond the study of this phenomenon (alteration).

Since the linguistics opposes this alteration, the contemporary linguists have attempted to interpret this phenomenon through holding a comparison between 
the sounds with its contrasting sounds in the Semitic languages, where the /9/ sound has been found that it does not exist except in Arabic, especially in the verb /a9ta/. As for other sematic languages, it is observed that the / $/ \mathbf{S}$ sound is contrasted to the sound /n/ in /ntn/ which means /aAta/ or gives in the Phoenician, Aramaic International, Palestinian Aramaic, and Munda'ia (Al-Theeb, 2006: p. 196). This has been found to be the same in Hebro with (natan) as well in Syriac Language (nettle) with the assimilation of the first $/ \mathrm{n} /$ in the / $/ \mathrm{t}$ and the second in the prepositional "La" (for) (Al-Theeb, 2006: p. 196). It was also found in Hebrew inscriptions, Palestinian Aramaic (Al-Theeb, 2006: p. 197). as /jatan/ meaning "to give". The word has also been found in as /janten/ in the Nabateans and Tadmurriyyah (Al-Theeb, 2006: p. 197).

Therefore, the resulting process is a kind of linguistic sculpture or derivation between Arabic and other Semitic languages where the first sound of the root (fa? al) is taken from the Semitic languages of close relations linguistically and geographically, and kept the central and last sound of the root as they are in Arabic. In this sense, Chaim Rabin attempted to link the verb "anta" to the verb (nata) in Hebrew in phrases as: "he spread his hand to me" (nāțāyāḍō >êl) meaning "took", and attempted to link the verb to the phrase "amtta althahr" meaning he gave him a ride such as horseback, a camel or a donkey to ride. This usage of the word was the source of the word "ride". Similarly emerged the word Ethiopian and Amharic languages (Ramadan, 1999a, 1999b: p. 122).

Rabin's interpretation relied on the analysis of both sounds / $/ \mathbf{S} /$ and $/ \mathrm{t} /$, compared the sounds of $/ \mathbf{S} /$ and $/ \mathrm{n} /$ in Hebrew and Arabic and their pronunciation development, and traced the effect of sound / $t /$ in Arabic to find that there has been a phonetic similarity between them as a result of development. For instance, the $/ \mathbf{S} /$ sound was pronounced as an aspired $/ \mathrm{n} /$ which required it to be a nasal sound in some locations as in the word "anta". The nasalized remained to indicate the original sound / / / as a nasal sound (Rabin, 1986, pp. 71-72). It is believed that Rabin remarked to this interpretation relying on what he observed in Arabic where the sound $/ \mathcal{I} /$ is extremely nasal as same as that of the orthodox Jews and the omission of this sound in the Hebrew of Safadiyyen Jews in western Europe where the pharyngeal sound was dropped from the sound / / / remaining in the form of the epiglottis sound /n/. If this is the case that Rabin relied on to interpret the phenomenon, he must be incorrect because European speakers of Hebrew were influenced by the environment they lived in which were free of the sound / / /.

According to Ibrahim Al-Samerrai, the Arabic verb could not be influenced by other languages. For example, the /n/ sound does not contrast the $/ \mathbf{S} /$ sound in the word "ata/"; rather, it comes from the form of "aata" in the sense that "he gave". This is evident in the Holy Quran, "and gave each one of them a knife" (Josef, verse 31). The sound then was doubled to be /atta/, and by unlocking the assimilation that requires the replacement of the $/ \mathrm{n} /$ sound in place of one of the heterogeneous sounds, the word becomes "anta" and then the light / $t$ / sound is replaced by the heavy /t/ sound which is very common in Arabic such as that of 
/nokktta/ and /noktah/. Although this explanation is a bit complicated, it can be strongly claimed that that the second form of the verb "anta" where its / $t$ / sound was replaced by the /tt/ sound is reasonable and accepted linguistically.

\subsection{Second Phenomenon}

Sibawaih (180 H.: p 199) interpreted this phenomenon stating "some Arabs add the $/ \mathrm{k} /$ sound to an $/ \mathrm{s} /$ sound to stress or clarify the femininity; however, they do so since the /s/ sound is an extra in the ruling verb /istafala/ (e.g. /a'taitikis/ and /akramakis/) and when they extend their speech acts, they drop the /s/ because the lower vowel gets clearer".

Therefore, it has been observed that the phenomenon is spread among the Arab tribes in spite of the fact that it is not common for all tribes to share all formats of the phenomenon. This explains the different views of linguists in relating this phenomenon to those tribes. Further, two formats of the phenomenon may be observed in the same tribe as is the case of Bani Bakr (Al-Mabrad, 285 H.: p 166) and the same for Al-Jouf "Skaka"'s people in the contemporary times. This means that two formats appear in the linguistic usage in one trine as follows:

First Format: the /k/ sound is mostly replaced by the /s/ sound especially by old people. Some original Sakakans remark that old people alter the $/ \mathrm{k} /$ sound to $/ \mathrm{s} /$ wherever it occurs in the word; however, younger generations is more influenced by the SA as a result of modern educational movement at schools and higher education institutions which emphasizes the use of SA. Some examples include the word /itsabid/ in the word "kabid", /itsalib/ in the word "kalb", /batsir/ in the word "bakir", /itsan/ in the word "kaan", /hatsi/ in the word "haki" and /itsif alhal/ in the phrase keif al-hal؟ (how are you?). However, Skakans have started to drop this phenomenon for their daily use wherever theses sounds occur, especially by younger generations who mix the use of old inherited altered words and those of modern format with no any alterations in their sounds at all. These younger generations use words such as /ktaab/, /kirsi/, and /bukra/ where they are still influenced by older generations i.e., the $/ \mathrm{k} /$ sound in $/ \mathrm{ktab} /$ is silent consonant and the / $/ \mathrm{k}$ in / kirsi/ is followed by /i/ movement reflecting the same influence.

Second Format. the $/ \mathrm{k} /$ sound in the addressed feminine speech such as /shlownits/ in the word /slownek? meaning (how are you?), /maGits/ in the wrd /maYk/ (with you), /akhbarits/ in the owrd /akhbarik/ meaning (whats up?) ans /hatsat/ in the word /hakat/ meaning (she said). This phenomenon is more common in the daily use with no observe changes particularly in the addressed feminine speech. However, when the $/ \mathrm{k} /$ sound is fixed or kept silent with no movement on, the preceding sound is followed by /i/ sound in the addressed masculine speech such as /shlonik/ in the word /shlownak/ meaning (how are you). The /its/ is found to be used to differentiate the masculine from feminine as a result of the SA differentiation between both i.e., masculine is marked by the /a/ sound and the feminine is marked by the /i/. This has not been found in 
Skakans' variation where the masculine /a/ movement has not done its function, nor has the /i./ done. The sound preceding / $\mathrm{k} /$ may be followed by /a/ movement in the addressed masculine speech to be said as, /shlonak/ but it remained irrelevant to Hail's people (Shammar).

Third Format: the addition of /s/ sound after the /k/ for addressed speech, as mentioned earlier, since it is not common in Skaka region whether by old or young generations.

Generally, in light of the above discussion, the phenomenon is not an alteration of the $/ \mathrm{s} /$ sound with the $/ \mathrm{k} /$ sound, rather it is noted that there are two sound: the $/ \mathrm{t} /$ and $/ \mathrm{s} /$ together instead of the $/ \mathrm{k} /$ sound. Linguists interpret it as the/k/ sound transfers to a double sound of /ts/ (Ramadan, 1999a, 1999b: p. 146) because such doubled sounds rend to break down to one of their original constituent sound as a result of development. Therefore, it can be strongly claimed that the kaskasa phenomenon where the $/ \mathrm{k} /$ sound is replaced by the $/ \mathrm{s} /$ sound is just a kind of development of the two doubled sounds /ts/ (Ramadan, 1999a, 1999b: pp. 148-149). This phenomenon is original among the Bedouin people in Najd desert and the Syrian desert (Carl, 1407 H.), which means that Skakan tribes brought it from those regions and tribes.

\subsection{Summary of Results}

This study found that the linguistic phenomena: Istintta and Kaskasa were normal manifestations of some SA dialects for some Arab tribes in the northern region of Saudi Arabia as can be seen in the above discussion. This implies that these phenomena were more likely used originally by those inhabited this region. The study further found that these linguistic phenomena have been affected by neighboring non-Arabic languages. Such influence took its place as a kind of linguistic sculpture or derivation between Arabic and other Semitic languages due to their close relations linguistically and geographically. However, these dialects were mostly ignored by old Arab linguists due to different complicated sociolinguistic factors which affected the record and history of these dialects negatively.

\section{Conclusion}

This research investigated two linguistic phenomena: Istintaa and Kaskaskah through collecting data from scripts, interviews, observation and other instruments. A mixed method of analysis was employed to find out that: the two Supra Segmental phenomena were normal for some Arab tribes in the north region of KSA and around of south borders of Jordan and Syrian desert. The research also found that these phenomena can be traced back to their strong relation with the old sematic languages especially Hebrew. The old Arab linguists avoided recording these phenomes within normal dialects of SA due to many reasons such as their misbelief that they are inferior because they are used by "inferior" tribes living around the borders. The research proved the strong relation between these 
two phenomena and some original standard Arabic scripts especially related to standard poetry and sacred Hadith of the prophet Mohammed PBUH.

It can be concluded that all languages are linguistically equal and the Istntaa and kskasah reflect normal and common dialects of great people. Therefore, these dialects should be under the focus of linguists' future further research. Finally, the region where this study was conducted is full of similar linguistic phenomena due to the intensive interaction between many people around the world throughout the history there, which implies that the region can be a rich source for historical and linguistic issues still in need to be resolved.

Therefore, implications of this research would refer to deepen scholar; s understanding of the origins and movement of some old and current spoken dialects of people particularly those who lived in the north of KSA. This research would also provide linguists with deeper insights into the phenomenon of Istnitaa and Kaskasah. More information about the Istintaa and Kaskasah as historically viewed as a representative of lower SA dialects would be provided for researcher to widen and spread their investigation in supra segmental phonology of Arabic dialects.

\section{Conflicts of Interest}

The authors declare no conflicts of interest regarding the publication of this paper.

\section{References}

Abu-Hayyan, M. (745 H., 2001). Interpretation of the Sea Ocean ((1), p. 520). Beirut: The Scientific Books House.

Al-Khattabi (388 H., 1982). The Strange Hadith (Tradition) (pp. 15, 281). Damascus: Rab al-Nabi, al-Fikr House.

Al-Mabrad, A. (285 H., 1997). The Complete in Language and Literature ((3), Volume 2, p. 166). Cairo: Al-Fikr al-Arabi House.

Al-Qurtubi, A. (671 H., 1964). The Collection of the Provisions of the Koran ((2), Volume 20, p. 216). Cairo: The Egyptian Book House.

Al-Suyuti, J. (1998). Al-Muzahr in Language Sciences and Types ((1), Volume 1, p. 176). Beirut: The Scientific Books House.

Al-Suyuti, J. (911 H.). Proficiency in the Sciences of Koran. In The Center of Quranic Studies, King Fahad Complex-Saudi Arabia (1).

Al-Theeb, S. (2006). Dictionary of Ancient Aramaic Vocabulary-Comparative Study ((1), pp. 196-197). Riyadh: King Fahad Library.

Al-Zamakhshari, A. (538 H.). The Outstanding in the Strange Hadith (Tradition) and Influence ((2), Volume 1, p. 17). Beirut: Al-Maarifa House.

Carl, B. (1407 H., 1977). Jurisprudence of Semitic Languages. Riyadh: Riyadh University Publications.

Cohen, L. (1977). Educational Research in Classrooms and Schools: A Manual of Materials and Methods. London: Harper \& Row.

Dexter, L. A. (1970). Elite and Specialized Interviewing. Evanston, IL: Northwestern Uni- 
versity.

Ibn-Fares, A. (1997). The Sahabi in the Philology of the Arabic Language and Its Issues, and the Sunan of Arabs' Talk (p. 29). Beirut: Muhammad Ali Baydoun's Publications.

Ibn-Fares, A. (395 H., 1991). Dictionary of Language Standards ((1), p. 128). Beirut: The Generation House.

Ibn-Manthoor, J. (711, 1414 H.). The Arabs Tongue ((3), Volume 15, p. 333). City: Sader House.

Keats, D. M. (2000). Interviewing-A Practical Guide for Students and Professionals. Buckingham: Open University Press.

Lofland, J., \& Lofland, L. H. (1984). Analyzing Social Settings (2nd ed.). Belmont, CA: Wadsworth.

Moser, C. A., \& Kalton, G. (1971). Survey Methods in Social Investigation (2nd ed.). London: Heinemann.

Rabin, C. (1986). Ancient West-Arabia. London: Taylor's Foreign Press.

Ramadan, A. T. (1417 H.). Introduction to Linguistics and Language Research Methods (3). Cairo: Al-Khanji Library.

Ramadan, A. T. (1997). Introduction to Linguistics and Language Research Methods. Cairo: Al-Khanji Library.

Ramadan, A. T. (1999a). Chapters in Arabic Philology ((1), p. 104). Cairo: Al-Khanji Library.

Ramadan, A. T. (1999b). Chapters in Arabic Philology ((6), p. 104). Cairo: Al-Khanji Library.

Sibawaih, A. (180 H., 1988). The Book ((3), Volume 4, p. 199). Cairo: Al-Khanji Library. 